\title{
INFORMATION TECHNOLOGY ETHICS: A RESEARCH FRAMEWORK
}

\author{
Richard V. McCarthy, Quinnipiac University, richard.mccarthy@ quinnipiac.edu \\ Leila Halawi, Nova Southeastern University, lahalawi@nova.edu \\ Jay E. Aronson, The University of Georgia, jaronson@uga.edu
}

\begin{abstract}
Information technology has become so pervasive that opportunities for abuses abound. IT Ethics has taken on increasing importance as the size and complexity of IT issues continues to grow. This paper outlines a research framework to analyze: Do significant ethical differences exist amongst undergraduate and graduate MIS students?
\end{abstract}

Keywords: Information Technology (IT), Ethics, IT and Ethics

\section{INTRODUCTION}

We live in an information society. Most people live and work within the context of information technology $[12,11]$. IT enhances leisure time and enriches culture by expanding the distribution of information, relieves pressures on urban areas by enabling individuals to work from home or remote-site offices [8], changes the way we work, and the way we work with one another. In terms of productivity and speed of communications, these changes have been mostly positive [15]. But what have been the costs? IT introduces change that creates new ethical issues.

Growing attention is being paid to ethics in IT curricula $[10,16]$. Several researchers have addressed subsets of the domain of IT ethics by assessing which actions are perceived by various subjects as ethical or unethical in a series of behavioral vignettes $[18,14,3]$. Others have developed or inferred theoretical frameworks, which have guided ethical assessments in either laboratory or field settings $[6,19]$. Another group of pioneering work include appeals to traditional philosophical theories as framework for ethical decision making in IT environs [9, 17].

Within the literature, one area that has not received significant attention is when do individuals begin to develop ethical attitudes and behaviors towards the use of information technology. In this paper, we present a framework for a research study to determine: Do significant differences exist between undergraduate and graduate students in their perception of IT ethics?

\section{Ethical Theories and IT}

Moore [13] suggested that the study of computer ethics is needed because there is a vacuum of policies surrounding the new possibilities. He defines computer ethics as the analysis of the nature and social impact of computer technology and the corresponding formulation and justification of policies for the ethical use of such a technology.

Ethical theories provide categories and procedures for determining what is ethically relevant. There are various avenues of ethical reasoning. Modern ethical theory can be divided into two broad categories: teleological and deontological. 
- Teleological ethical theories focus primarily on the consequences, results, ends, goals or purposes of agent acts. They give priority to the good over the right, and they evaluate actions by the goal or consequences that they attain. Utilitarianism, a form of consequentialism, a theory predicted on the assumption that consequences determine the rightness or wrongness of moral actions is an example of teleological approach to ethics [20].

- Deontological ethical theories center on the act taken by the agent and the duties, rights, privileges or responsibilities that pertain to that act. According to a deontological framework, actions are intrinsically right or wrong regardless of the consequences they produce. Deontological theories include both duty-based and rights-based approaches to ethical reasoning, sometimes referred to as pluralism or contractarianism respectively [20].

The fundamental difference between the two is that deontological perspectives focus on the specific actions or behaviors of an individual while teleological perspectives focus on the consequences of the actions.

Within an MIS context, a strict deontologist might view copying software as inherently unethical, and would oppose this practice no matter what the circumstances. A strict teleologist, on the other hand, might examine the possible positive consequences for himself and the firm (e.g., increased productivity and cost savings) and weigh these against the possible negative consequences if the firm were to be prosecuted (e.g., possible damages and negative publicity). [7].

Topics within the IT ethics literature may be generally partitioned into three categories (Table 1). The first considers broad, social implications of IT practices. A second focuses on identifying differences between MIS and other professionals. The third category considers the impact of technology on decision-making processes [18].

Table 1. Categories of MIS/Ethics Related Research

\begin{tabular}{lll} 
Area & Reference & Description \\
\hline Social Aspects & Johnson (1984) & $\begin{array}{l}\text { Outlined the characteristics for a } \\
\text { computer society ethic }\end{array}$ \\
& Johnson (1985) & $\begin{array}{l}\text { Identified ethical issues regarding } \\
\text { computer use from a contemporary } \\
\text { philosophical viewpoint. }\end{array}$ \\
& Mason (1986) & $\begin{array}{l}\text { Identified privacy, accuracy, property, } \\
\text { and accessibility as four ethical issues of } \\
\text { the information age. }\end{array}$ \\
Group Differences & Paradice \& Davis (1990) & $\begin{array}{l}\text { Compared IS and non-IS students. } \\
\text { The frequency and opportunity for } \\
\text { unethical behavior by MIS professionals } \\
\text { is examined empirically. }\end{array}$
\end{tabular}


Paradice \& Dejoie (1991)

Abratt et al. (1992)

Morris et al. (1993)

Athey (1993)

Benham \& Wagner (1995)

Sumner \& Werner (1997)

Technology Effects Bommer et al. (1987)
An empirical investigation was conducted to determine whether MIS majors, exhibit ethical decision-making processes that differ from students in other functional business areas, and whether the existence of a computer based information system in an ethical dilemma influences ethical decision making.

Compared the ethical beliefs of managers operating in South Africa and Australia.

Hypothesized that South African entrylevel IS personnel find a broader range of ethical dilemmas to be more acceptable compared to their American counterparts.

Hypothesized that students preparing to enter the business world as computer professionals hold the same beliefs as the more experienced group.

Compared the ethical attitudes of business students and MIS personnel.

Compared the attitudes of students (Freshman, MIS majors) and practitioners.

Hypothesized that information filtering and presentation affects ethical behavior.

\section{RESEARCH METHODOLOGY}

Our research centered upon the following research question:

Do significant ethical differences exist amongst undergraduate and graduate MIS students in the United States?

The research hypotheses to be tested are:

$\mathrm{H}_{1}$ : Computer information systems undergraduate and graduate students have the same ethical beliefs 
$\mathrm{H}_{2}$ : $\quad$ Female computer information systems students and male computer information systems students have the same ethical beliefs.

$\mathrm{H}_{3}$ : Computer information system graduate students exhibit the same ethical beliefs as MBA graduate students.

To test these hypotheses a subset of five ethical scenarios that were utilized by Athey [1] to test if significant ethical differences existed amongst manager was used along with one ethical scenario that was developed based upon an actual case from the researcher's university. The scenario technique has been shown to be useful in eliciting attitudes by personalizing the issues [5].

The sample population consisted of undergraduate and graduate students from a medium sized university located in the northeast United States. The graduate students were comprised of students who are either in Masters in Computer Information Systems or Master of Business Administration programs. The scenarios were personally administered.

\section{RESULTS}

Eighty-seven scenarios were administered and the demographics of the sample population are shown in Table 2. The sample population had more males (70.1\%) than females (29.9\%).

Table 2. Demographics

\begin{tabular}{llc} 
Gender & Program & Responses \\
\hline Female & Undergraduate CIS student & 4 \\
& Graduate CIS student & 6 \\
& Graduate MBA student & 16
\end{tabular}

$\begin{array}{lll}\text { Male } & \text { Undergraduate CIS student } & 27 \\ & \text { Graduate CIS student } & 19 \\ \text { Graduate MBA student } & 15\end{array}$

A Chi-Square test was performed to test each of the three hypotheses. The first hypothesis tested whether undergraduate and graduate computer information systems students hold the same ethical beliefs. Responses from MBA students were not considered as part of this analysis. A pvalue was calculated for each of the six scenarios and any value less than .05 was rejected. Scenarios 2 and 6 were rejected on this basis, but scenarios 1, 3, 4, and 5 were accepted. The second hypothesis tested whether female and male computer information systems students hold the same ethical beliefs. Responses from MBA students were not considered as part of this analysis. A p-value was calculated for each of the six scenarios and any value less than .05 was rejected. Scenarios 1, 2, 3 and 6 were rejected on this basis, but scenarios 4 and 5 were accepted. The third hypothesis tested whether computer information systems graduate students and masters of business administration graduate students hold the same ethical beliefs. Responses from undergraduate students were not considered as part of this analysis. A p-value was calculated for each of the six scenarios and none of the scenarios exhibited a value less than .05. 


\section{CONCLUSIONS}

It was very clear from the responses that there were no significant differences in ethical beliefs amongst MBA and MS-CIS graduate students. It should be noted that in both cases the students had not received formal training related to computer ethics within there program of study, though in both cases the topic was covered in sections within their curriculum. The curriculum for the MBA students is changing next year to include a formal course in business ethics that will include information technology related topics.

Though the support was not as strong there was support that significant differences do not exist between undergraduate and graduate computer information systems students. One limitation to our study however, is that there were significantly more male students than female students which may have influenced this result. The undergraduate students that participated in this study had received instruction in information technology ethics as part of their curriculum, including case study analysis.

Based upon the results of our study, we concluded that significant differences existed between male and female computer information systems students in their ethical beliefs. Though as noted previously, there was a small sample population of female students. This is significant because it supports the industry study gender differences that show that software piracy and hacking tend to be more prevalent amongst males than females.

The IS2002 model curriculum [22] recommends that formal instruction in ethics be included in the curriculum of information technology programs. Our research supports that contention.

\section{REFERENCES}

1. Abratt, R., Nel D., \& Higgs, S. N.(1992). An examination of the ethical beliefs of managers using selected scenarios in a cross-cultural environment. Journal of Business Ethics, 11(1), 29-35.

2. Athey S. (1993). A comparison of experts and high tech students' ethical beliefs in computerrelated situations. Journal of Business Ethics, 12, 359-370

3. Benham, H. C., \& Wagner, J. L. (1995). Ethical attitudes of business students and MIS personnel. Proceedings of the ACM SIGCPR Conference [online], Nashville TN USA, 44-49. Available: www.acm.org/pubs/articles/proceedings/cpr/212490/p44-wagner/p44-wagner.pdf

4. Bommer, M., Gratte, C., Gravander, J., \& Tuttle, M. (1987). A behavioral model of ethical and unethical decision making. Journal of Business Ethics, 6(4), 265-280.

5. Couger, D. J. (1989). Preparing IS students to deal with ethical issues. MIS Quarterly, 13(2), 211-218.

6. Culnan, M. J. (1993). How did they get my name? An exploratory investigation of consumer attitudes toward secondary information use. MIS Quarterly, 17(3), 341-363.

7. Davis, D. L., \& Vitell, S. J. (1990). Ethical beliefs of MIS professionals: the frequency and opportunity for unethical behavior. Journal of Business Ethics, 9, 63-70.

8. Gates, B. (1995). The road ahead. Viking Penguin Group.

9. Laudon, K. C. (1995). Ethical Concepts and Information Technology. Communication of the ACM, 38(12), 33-39. 
10. Loch, K.D., \& Conger, S. (1996). Evaluating ethical decision making and computer use. Communications of the ACM, 39(7), 74-83.

11. Mason, R.O. (1986). Four ethical issues of the information age. MIS Quarterly, 10(1), 4-12.

12. Mason, R.O., Mason, F. M., \& Culnan, M. J. (1995). Ethics of Information Management. Thousand Oaks, CA:Sage publications.

13. Moore, J. H. (1985). What is computer ethics. Metaphilosophy, 16(4), 266-275.

14. Morris, A., Jones, G. \& Rubinsztein, J. (1993). Entry-level information systems personnel: a comparative study of ethical attitudes. Proceedings of the 1993 ACM SIGCPR Conference. [online] St Louis MoUSA, 8-17. Available Ww.acm.org/pubs/articles/proceedings/cpr/158011/p8-morris/p8-morris.pdf

15. Mujica, A., Petry, E., \& Vickery, D. (1999). A future for technology and ethics. Business \& Society Review, 104 (3), 279-290.

16. Oz, E. (1992). Ethical standrads for information systems professionals: A case for a unified code. MIS Quarterly, 16(4), 423-433.

17. Oz, E. (1994). Ethics for the information age. Irwin/McGraw-Hill, New York..

18. Paradice, D. B., \& Dejoie, R. M. (1991). The ethical decision-making processes of information systems workers. Journal of Business Ethics, 10, 1-21.

19. Smith, J. H. (1993). Privacy policies and practices: inside the organizational maze. Communications of the ACM, 36(12), 105-122.

20. Spinello, R. A. (1995). Ethical aspects of information technology. Englewood Cliffs, NJ: Prentice Hall.

21. Summer, M., \& Werner, K. (1997). On-line ethics: A comparison of the attitudes of freshmen, MIS majors, and practitioners. Proceedings of the 1997 conference on computer personnel research. www.is2002.org, retrieved December 17, 2004. 